FEDERAL RESERVE BANK OF SAN FRANCISCO

WORKING PAPER SERIES

\title{
Private Capital Flows, Capital Controls, and Default Risk
}

\author{
Mark L. J. Wright \\ Stanford University
}

August 2004

Working Paper 2004-34

http://www.frbsf.org/publications/economics/papers/2004/wp04-34bk.pdf

This paper was presented at the conference on "Emerging Markets and Macroeconomic Volatility: Lessons from a Decade of Financial Debacles" cosponsored by the Center for Pacific Basin Studies of the Federal Reserve Bank of San Francisco and the Center for International Economics at the University of Maryland and held at the FRBSF on June 4-5 2004. The views in this paper are solely the responsibility of the authors and should not be interpreted as reflecting the views of the Federal Reserve Bank of San Francisco or the Board of Governors of the Federal Reserve System 


\title{
Private Capital Flows, Capital Controls, and Default Risk*
}

\author{
Mark L.J. Wright ${ }^{\dagger}$
}

May 21, 2004

\begin{abstract}
What has been the effect of the shift in emerging market capital flows toward private sector borrowers? Are emerging markets capital flows more efficient? If not, can controls on capital flows improve welfare? This paper studies these questions in a world with two forms of default risk. When private loans are enforceable, but there is the risk of national default, constrained efficient capital flows can be decentralized with private borrowing subject to individual borrowing constraints: no capital controls are necessary. However, when private agents may individually default, private lending is inefficient, and capital flow subsidies are potentially Pareto-improving.

JEL Classification: F21, F34, F41, O19.

Keywords: Capital flows, default, decentralization, borrowing constraints, capital subsidies.
\end{abstract}

\footnotetext{
${ }^{*}$ I thank, without implicating, Fernando Alvarez, Christine Groeger, Narayana Kocherlakota, and Robert Martin for comments.

${ }^{\dagger}$ Department of Economics, Stanford University, 579 Serra Mall, Stanford CA 94305-6072. Telephone: (650) 725-9967. Fax: (650) 725-5702. Email: mlwright@stanford.edu.
} 


\section{INTRODUCTION}

Capital flows to emerging markets have shifted markedly away from public sector and towards private sector borrowers. In the past decade, the private sector share of the stock of emerging market debt rose more than five-fold from around five per-cent in 1990 to more than one-quarter of the total by the end of the Century. Private nondebt capital flows have also increased rapidly, with gross foreign direct investment as a share of all private capital inflows more than doubling over the same period.

The rise in private capital flows has been accompanied by an increased interest in, and some cases application of, capital controls. In the decade of the 1990's, a number of countries, including most famously Brazil and Chile, introduced controls to limit short term inflows on capital, while others, most notably Spain, Malaysia and Thailand, introduced controls to limit outflows of capital. And while many of these actual experiences with controls were justified as temporary measures in the face of a crisis, there have been increasing calls for controls to be used both as a tool for macroeconomic management, and to correct other financial market imperfections. ${ }^{1}$

What has been the effect of this shift in emerging market capital flows? Are emerging market capital flows more efficient as a result? And if not, can government intervention in the form of capital controls improve welfare? In this paper, we study the form and efficiency of private capital flows in the face of different forms of default risk and show that restrictions on capital flows are not justified as a remedy for these capital market imperfections. We go on to show that, depending on the precise form

\footnotetext{
${ }^{1}$ Ariyoshi (3) provides an excellent review of country experiences with capital controls, and the various arguments in favor of their use. The International Monetary Funds changing views on capital controls are summarized in the IMF Survey of May 19, 2003 (the public reaction to which is contained in The Economist "A Slightly Circuitous Route" and "A Place for Capital Controls", May 1st, 2003).
} 
of default risk facing foreign investors, government intervention is potentially Pareto improving. However, in these cases the optimal form of government intervention takes the form of a subsidy, and not a restriction, on private capital flows.

In developing these arguments we distinguish between two forms of default risk. When the government of a developing country provides for the enforcement of private contracts between residents and foreigners, but can default on the nations entire borrowings, we say that foreign investors face national default risk, and show that the constrained efficient allocations can be decentralized in a competitive equilibrium with private borrowing subject to individual borrowing constraints. That is, private borrowing is efficient and there is no scope for Pareto improving government intervention. However, when the countries legal system does not enforce private contracts with foreigners, so that foreign investors also face resident default risk, private borrowing is inefficient, and government intervention in the form of a borrowing subsidy is potentially Pareto improving. In neither case is there a justification for capital controls.

Both forms of default risk are important in practice. Historically national default risk has been a consequence of the doctrine of sovereign immunity which prohibited legal action against a sovereign state. Although this doctrine has been eased over time, the process of attaching assets remains difficult as many debtor countries have little in the way of foreign assets. Moreover, national default risk extends beyond the borrowings of the government itself to include default on private contracts either directly, by nationalizing private industries or taxing foreign remittances, or indirectly by imposing capital controls and other measures that prevent residents from honoring their obligations. Resident default risk, on the other hand, results from the failure of domestic contract enforcement institutions to enforce foreign claims on domestic residents. In some cases, this is as a result of judicial corruption ${ }^{2}$. However, even in

\footnotetext{
${ }^{2}$ Judicial partiality is commonly cited as an important component of corruption in emerging
} 
developed countries the ability to use domestic courts to force fulfillment of a contract can be difficult, as illustrated by the Japan-Australia sugar dispute in which a group of Japanese sugar refiners refused to honor contracts after world sugar prices fell dramatically (see, for example, March (12)).

We begin by outlining a simple model of capital flows in the face of default risk and show that the constrained efficient allocations can be decentralized as a competitive equilibrium in which individual residents borrow subject to individual borrowing constraints. These borrowing constraints on individual agents serve to deter the economy as a whole from accumulating debt to the point where the national government would choose to default. As the allocations are constrained efficient, no government intervention is required.

We then introduce the possibility of resident default risk, and show that the resulting competitive equilibrium exhibits capital flows that are inefficiently low. The reason is that if a defaulting resident is excluded from direct access to international financial markets they can continue to access these markets using other domestic agents as intermediaries. The weaker punishment supports less lending in equilibrium.

This inefficiency suggests a potential role for Pareto-improving government intervention. Presuming that it is not possible to directly strengthen the domestic contract enforcement institutions, or to indirectly do so via a mechanism such as a tax on default, we look for a mechanism that treats all agents symmetrically. Specifically, we show that the efficient allocations can be attained through a policy of subsidizing access to international financial markets. The reason is that a subsidy makes default less attractive by increasing the value of access to international capital markets.

This paper builds on a substantial literature on trade in financial assets in the markets. The World Bank's World Development Report of 1997 emphasized a lack of predictability in court rulings as a constraint on foreign investment. Al-Kilani (1) presents evidence that discrimination on the basis of nationality is common in middle eastern legal proceedings. 
presence of enforcement frictions. One strand of this literature studies international debt in the presence of default risk, and has been surveyed by Eaton and Fernandez (7). For the most part, this literature focuses on public sector lending, and assumes that a country is associated with a representative agent that makes all borrowing and default decisions on behalf of a countries residents ${ }^{3}$. In contrast, in this paper we examine borrowing by private agents in the face of this risk, and show how the allocations obtained in this earlier literature might result out of the interaction of private agents in a competitive equilibrium. Another strand of this literature looks at the effects of enforcement frictions in closed economy debt markets, as in Alvarez and Jermann (2) and Kehoe and Levine (11). Where the current paper differs is in drawing a distinction between the borrowing decision and the default decision (when private agents borrow subject to national repudiation risk), and in studying the interaction of enforcement frictions in international markets and the lack thereof in domestic markets (which allows residents who have defaulted to continue accessing international markets using other residents as intermediaries).

In two recent papers, Jeske (9) and Kehoe and Perri (10) study borrowing by private agents in environments subject to default risk and argue that efficient allocations require the imposition of capital controls. Jeske studies resident default risk and shows that prohibitive capital controls combined with a centralized mechanism for international borrowing can obtain the constrained efficient level of borrowing. Kehoe and Perri study an economy with national repudiation risk and show that private agents can be induced to borrow efficiently by government taxes on capital flows. By contrast, this paper analyzes environments with both national and resident default risk and shows that capital controls are not necessary for efficiency.

The rest of this paper is organized as follows. Section Two outlines the modeling environment, characterizes the constrained efficient allocations and establishes that,

\footnotetext{
${ }^{3}$ Exceptions include Cole and English (4) and (5), and Chang (6).
} 
as long as individuals (but not the country as a whole) can commit to honor contracts with foreigners, the efficient allocations can be decentralized in a framework where private individuals make their own borrowing decisions. No government intervention is needed. Section Three shows that when individual agents both borrow and make their own default decisions the competitive equilibrium allocations are inefficient and that a government borrowing subsidy can be used to increase welfare. Section Four presents the results from a simple example, which can be computed by hand, and uses them to illustrate the differences between the various formulations, while Section Five concludes.

\section{NATIONAL DEFAULT RISK}

\section{Constrained Efficient Allocations with National Default Risk}

Consider a world economy populated by a finite number of countries denoted $m=$ $1, \ldots, M$. Each country $m$ is populated by $N$ types of agents. We will use subscripts to denote types of individuals and superscripts to denote countries, so that $\lambda_{n}^{m}>0$ denotes the measure of agents of type $n$ in country $m$. Time is discrete and in each period $t=0,1,2 \ldots$ information about current and future endowments is indexed by the state $\theta_{t}$, an element of the finite set $\Theta$. Information about states forms a Markov chain, and the transition probability from $\theta$ to $\theta^{\prime}$ is given by $\pi\left(\theta^{\prime} \mid \theta\right)$ with the initial state $\theta_{0}$ given. We let $\theta^{t}:=\left(\theta_{0}, \theta_{1}, \ldots, \theta_{t}\right) \in \Theta^{t}$ denote a history of states up to date $t$. The notation $\theta^{s} \mid \theta^{t}$ for $s>t$ refers to a history $\theta^{s}$ that continues $\theta^{t}$ in the sense that $\theta^{s}=\left(\theta^{t}, \theta_{t+1}, \theta_{t+2}, \ldots, \theta_{s}\right)$. The probability of observing history $\theta^{t}$ is denoted by $\pi(\theta)^{t}$, and that of observing history $\theta^{s}$ conditional on having been in $\theta^{t}$ is $\pi\left(\theta^{s} \mid \theta^{t}\right)$.

There is one non-storable good available for consumption in each history. A state $\theta$ specifies a vector of endowments for each type of agents in each country. We 
denote by $e_{n}^{m}\left(\theta^{t}\right)$ the endowment of a type $n$ agent in country $m$ after history $\theta^{t}$ and by $c_{n}^{m}\left(\theta^{t}\right)$ the corresponding consumption level. It will be convenient to define, for all countries $m$ and for all histories $\theta^{t}$, the aggregate endowment of a country, $m$, as $e^{m}\left(\theta^{t}\right)=\sum_{n=1}^{N} \lambda_{n}^{m} e_{n}^{m}\left(\theta^{t}\right)$ and the aggregate consumption level of country $m$ as $c^{m}\left(\theta^{t}\right)=\sum_{n=1}^{N} \lambda_{n}^{m} c_{n}^{m}\left(\theta^{t}\right)$.

Individuals have preferences ordered by a time additively separable function

$$
\sum_{t=0}^{\infty} \beta^{t} \sum_{\theta^{t}} \pi\left(\theta^{t}\right) U_{n}^{m}\left(c\left(\theta^{t}\right)\right)
$$

where $\beta \in(0,1)$ is the discount factor of an agent, which is assumed the same over all types, while the function $U_{n}^{m}$ is the period utility function which is strictly increasing and strictly concave.

In the presence of national default risk, capital flows between countries must be such that they are nationally self-enforcing: an allocation must deliver the residents of a nation sufficient utility to deter their national government from defaulting on their behalf. It is assumed that each national government is benevolent with respect to its own citizens and acts to maximize a weighted average of their lifetime utilities where $\phi_{n}^{m}>0$ is the weight assigned to agents of type $n$ by the government of country $m$. We allow governments to make arbitrary date zero transfers between agents.

In this environment, a consumption allocation $c=\left\{c_{n}^{m}\left(\theta^{t}\right)\right\}_{n, m, \theta^{t}, t}$ is resource feasible if it is non-negative and satisfies

$$
\sum_{m=1}^{M} \sum_{n=1}^{N} \lambda_{n}^{m} c_{n}^{m}\left(\theta^{t}\right) \leq \sum_{m=1}^{M} \sum_{n=1}^{N} \lambda_{n}^{m} e_{n}^{m}\left(\theta^{t}\right)
$$

for all $t$ and all $\theta^{t}$. A consumption allocation satisfies the sequence of national participation constraints if it satisfies

$$
\sum_{n=1}^{N} \phi_{n}^{m} \sum_{s>t} \beta^{s-t} \sum_{\theta^{s} \mid \theta^{t}} \pi\left(\theta^{s} \mid \theta^{t}\right) U_{n}^{m}\left(c_{n}^{m}\left(\theta^{t}\right)\right) \geq D^{m}\left(\theta^{t}, \phi^{m}\right)
$$


for all $m, t$ and for all $\theta^{t}$. The constraint (2) states that the continuation of an allocation for a country $m$ must, after each history, deliver at least as much weighted lifetime utility as default to autarky for that country as a whole. We denote the latter by $D^{m}\left(\theta^{t}, \phi^{m}\right)$, which is calculated by maximizing the $\left\{\phi_{n}^{m}\right\}$-weighted average of residents utilities subject to the constraint that $c^{m}\left(\theta^{t}\right)$ not exceed $e^{m}\left(\theta^{t}\right)$.

In this environment, an allocation is constrained efficient if it satisfies resource and incentive feasibility, and there is no other allocation satisfying these constraints that is strictly Pareto-preferred. To characterize the set of constrained efficient allocations, let $\varphi^{m}>0$ denote the Pareto weight attached to the welfare of country $m$ by the international social planner, and for convenience normalize $\sum_{n} \phi_{n}^{m}=1$. We can characterize the set of efficient allocations by solving the following convex planning problem

$$
\max _{c} \sum_{m=1}^{M} \varphi^{m} \sum_{n=1}^{N} \phi_{n}^{m} \sum_{t=0}^{\infty} \beta^{t} \sum_{\theta^{t}} \pi\left(\theta^{t}\right) U_{n}^{m}\left(c_{n}^{m}\left(\theta^{t}\right)\right),
$$

subject to the sequence of resource and incentive feasibility constraints in (1) and (2).

The strong separability embodied in this problem implies that the solution to the planning problem in $(\mathrm{PP})$ can be found in two stages. In the second stage, aggregate country consumption is taken as given at $c^{m}\left(\theta^{t}\right)$ and is allocated between residents of a country to maximize the $\left\{\phi_{n}^{m}\right\}$-weighted average of their utilities defined as $V^{m}\left(c^{m}\left(\theta^{t}\right), \phi^{m}\right)$. In the first stage, the planner allocates consumption between countries to

$$
\max _{c} \sum_{m=1}^{M} \phi^{m} \sum_{t=0}^{\infty} \beta^{t} \sum_{\theta^{t}} \pi\left(\theta^{t}\right) V^{m}\left(c^{m}\left(\theta^{t}\right), \phi^{m}\right)
$$

subject to

$$
\sum_{m=1}^{M} c^{m}\left(\theta^{t}\right) \leq \sum_{m=1}^{M} e^{m}\left(\theta^{t}\right)
$$

for all $t$, and

$$
\phi^{m} \sum_{s>t} \beta^{s-t} \sum_{\theta^{s} \mid \theta^{t}} \pi\left(\theta^{s} \mid \theta^{t}\right) V^{m}\left(c^{m}\left(\theta^{t}\right), \phi^{m}\right) \geq D^{m}\left(\theta^{t}, \phi^{m}\right),
$$


for all $m$ and all $t$. The above result is useful because it allows us to solve a limited commitment problem at an international level to determine the efficient level of intertemporal trade between countries before later allocating these goods between residents of a country. Unfortunately, the solution of this problem requires knowledge of the appropriate country weights $\phi^{m}$ which determine the form of the period country welfare functions $V^{m}\left(c^{m}\left(\theta^{t}\right), \phi^{m}\right)$ as well as the default values $D^{m}\left(\theta^{t}, \phi^{m}\right)$. The following proposition shows that if preferences are homothetic and identical within a country (so that $U_{n}^{m}=U^{m}$ for all $n$ ), international capital flows will be independent of these weights. In particular, the solution of the two-stage problem can be computed by first solving the first stage for a representative agents with preferences given by $U^{m}$.

Proposition 1 If preferences are homothetic and identical within a country, capital flows are independent of country welfare weights $\phi^{m}$.

Proof. Consider the two stage problem substituting $U^{m}$ for $V^{m}\left(c^{m}\left(\theta^{t}\right), \widehat{\phi}^{m}\right)$. In the second stage, with preferences identically homothetic within the country, we have

$$
\frac{u^{\prime}\left(c^{m}\left(\left(\theta^{t}, \theta_{t+1}\right)\right)\right)}{u^{\prime}\left(c^{m}\left(\theta^{t}\right)\right)}=\frac{u^{\prime}\left(c_{n^{\prime}}^{m}\left(\left(\theta^{t}, \theta_{t+1}\right)\right)\right)}{u^{\prime}\left(c_{n}^{m}\left(\theta^{t}\right)\right)},
$$

for all $n, n^{\prime}$, periods $t$, and histories $\theta^{t}$, which implies the first order conditions of the planning problem.

Obviously, the solution to the two-stage problem satisfies resource feasibility for the planning problem. To show that it satisfies the participation constraints, note that by construction it satisfies for all $\theta^{t}$

$$
\sum_{s>t} \beta^{s-t} \sum_{\theta^{s} \mid \theta^{t}} \pi\left(\theta^{s} \mid \theta^{t}\right) U^{m}\left(c^{m}\left(\theta^{t}\right)\right) \geq \sum_{s>t} \beta^{s-t} \sum_{\theta^{s} \mid \theta^{t}} \pi\left(\theta^{s} \mid \theta^{t}\right) U^{m}\left(e^{m}\left(\theta^{t}\right)\right) .
$$

The result will then follow if we can establish that the function

$$
h(x)=\sum_{n=1}^{N} \phi_{n}^{m} U^{m}\left(\alpha_{n}\left(U^{m}\right)^{-1}(x)\right)
$$


is affine and strictly increasing. For then

$h\left(\sum_{s>t} \beta^{s-t} \sum_{\theta^{s} \mid \theta^{t}} \pi\left(\theta^{s} \mid \theta^{t}\right) U^{m}\left(c^{m}\left(\theta^{t}\right)\right)\right) \geq h\left(\sum_{s>t} \beta^{s-t} \sum_{\theta^{s} \mid \theta^{t}} \pi\left(\theta^{s} \mid \theta^{t}\right) U^{m}\left(e^{m}\left(\theta^{t}\right)\right)\right)$,

implies

$$
\sum_{s>t} \beta^{s-t} \sum_{\theta^{s} \mid \theta^{t}} \pi\left(\theta^{s} \mid \theta^{t}\right) h\left[U^{m}\left(c^{m}\left(\theta^{t}\right)\right)\right] \geq \sum_{s>t} \beta^{s-t} \sum_{\theta^{s} \mid \theta^{t}} \pi\left(\theta^{s} \mid \theta^{t}\right) h\left[U^{m}\left(e^{m}\left(\theta^{t}\right)\right)\right],
$$

and hence

$$
\begin{aligned}
& \sum_{n=1}^{N} \phi_{n}^{m} \sum_{s>t} \beta^{s-t} \sum_{\theta^{s} \mid \theta^{t}} \pi\left(\theta^{s} \mid \theta^{t}\right) U^{m}\left(c_{n}^{m}\left(\theta^{t}\right)\right) \\
= & \sum_{n=1}^{N} \phi_{n}^{m} \sum_{s>t} \beta^{s-t} \sum_{\theta^{s} \mid \theta^{t}} \pi\left(\theta^{s} \mid \theta^{t}\right) U^{m}\left(\alpha_{n} c^{m}\left(\theta^{t}\right)\right) \\
\geq & \sum_{n=1}^{N} \phi_{n}^{m} \sum_{s>t} \beta^{s-t} \sum_{\theta^{s} \mid \theta^{t}} \pi\left(\theta^{s} \mid \theta^{t}\right) U^{m}\left(\alpha_{n} e^{m}\left(\theta^{t}\right)\right)=D^{m}\left(\theta^{t}\right),
\end{aligned}
$$

where the last equality comes from identical homotheticity.

To see that $h$ is affine and strictly increasing, note that the derivative of $h$ is

$$
h^{\prime}(x)=\sum_{n=1}^{N} \frac{\phi_{n}^{m} U^{m \prime}\left(\alpha_{n}\left(U^{m}\right)^{-1}(x)\right) \alpha_{n}}{U^{m \prime}\left(\left(U^{m}\right)^{-1}(x)\right)}=\sum_{n=1}^{N} \phi_{n}^{m} \alpha_{n} \frac{U^{m \prime}\left(\alpha_{n} c\right)}{U^{m \prime}(c)},
$$

where $c=\left(U^{m}\right)^{-1}(x)$. But as $U^{m}$ is identically homothetic, $U^{m \prime}\left(\alpha_{n} c\right) / U^{m \prime}(c)$ is a constant for all $c$.

\section{Decentralization with Private Borrowing and National Default}

In this subsection we show that, as long as domestic courts enforce contracts with foreigners, the efficiency of private capital flows is constrained only by the ability 
of the national government to default. That is, the constrained efficient allocation can be decentralized. The key lies in establishing a mechanism by which individual agent borrowing is constrained so that the nation as a whole, as represented by its government, has no incentive to default.

It is assumed that there exists a full set of state contingent one-period international Arrow securities, and with prices denoted by $q\left(\theta^{t}, \theta_{t+1}\right)$, for securities purchased after history $\theta^{t}$ for payment in period $t+1$ after observing event $\theta_{t+1}$. We let $b_{n}^{m}\left(\theta^{t}, \theta_{t+1}\right)$ is the holdings of these securities by a type $n$ agent in country $m$. Using these prices we can define the time zero Arrow-Debreu price on international markets of a unit of consumption at time $t$ after realization of history $\theta^{t}$ as

$$
Q\left(\theta^{t} \mid \theta_{0}\right)=q\left(\theta_{0}, \theta_{1}\right) q\left(\theta^{1}, \theta_{2}\right) \cdots q\left(\theta^{t-1}, \theta_{t}\right)
$$

The problem of a resident of type $n$ of country $m$ in this decentralization is to choose sequences for consumption and securities holdings to maximize

$$
\sum_{t=0}^{\infty} \beta^{t} \sum_{\theta^{t}} \pi\left(\theta^{t}\right) U_{n}^{m}\left(c\left(\theta^{t}\right)\right)
$$

subject to

$$
c\left(\theta^{t}\right)+\sum_{\theta_{t+1}} q\left(\theta^{t}, \theta_{t+1}\right) b_{n}^{m}\left(\theta^{t}, \theta_{t+1}\right)=e_{n}^{m}\left(\theta^{t}\right)+b_{n}^{m}\left(\theta^{t-1}, \theta_{t}\right)
$$

for all $\theta^{t}=\left(\theta^{t-1}, \theta_{t}\right)$ for all $t$, and

$$
b\left(\theta^{t}, \theta_{t+1}\right) \geq-\bar{B}_{n}^{m}\left(\theta^{t}, \theta_{t+1}\right)
$$

for all $\theta^{t}$ for all $t$, with $b\left(\theta^{0}\right)$ given. Here, $\bar{B}_{n}^{m}\left(\theta^{t}, \theta_{t+1}\right)$ is a borrowing constraint that is set so as to prevent agents from accumulating so much debt that their government is tempted to default on their behalf. A weaker constraint of this form would be necessary to rule out the possibility of Ponzi debt schemes, even in the absence of the possibility of national repudiation. Following Alvarez and Jermann (2), the 
constraint in (3) will be referred to as a solvency constraint and is type, country and history dependent. This leads to our definition of a competitive equilibrium with solvency constraints.

Definition 2 A competitive equilibrium with solvency constraints is a sequence of solvency constraints $\bar{B}_{n}^{m}\left(\theta^{t}, \theta_{t+1}\right)$ for all countries $m$, types $n$, dates $t$ and histories $\theta^{t}$, a price system $\left\{q\left(\theta^{t}, \theta_{t+1}\right)\right\}$ for all countries $m$, dates $t$, and histories $\theta^{t}$, and an allocation $\left\{c_{n}^{m}\left(\theta^{t}\right), b_{n}^{m}\left(\theta^{t}, \theta_{t+1}\right)\right\}$ such that for all countries $m$ and types $n$, the allocation solves the residents problem given the price system, solvency constraints, and initial asset holdings, and markets clear. That is, for all dates $t$ and all histories $\theta^{t}$, goods markets clear

$$
\sum_{m=1}^{M} \sum_{n=1}^{N} \lambda_{n}^{m} c_{n}^{m}\left(\theta^{t}\right) \leq \sum_{m=1}^{M} \sum_{n=1}^{N} \lambda_{n}^{m} e_{n}^{m}\left(\theta^{t}\right)
$$

and for all $\theta_{t+1}$ the markets for securities clear

$$
\sum_{m=1}^{M} \sum_{n=1}^{N} \lambda_{n}^{m} b_{n}^{m}\left(\theta^{t}, \theta_{t+1}\right)=0
$$

Let $W_{n}^{m}\left(b, \theta^{t}\right)$ be the value to a resident of type $n$ in country $m$ who begins at history $\theta^{t}$ with bond holdings $b$. The functional equation for this agent defines $W_{n}^{m}\left(b, \theta^{t}\right)$ as

$$
\max _{c,\left\{b^{\prime}, f^{\prime}\right\}}\left\{U(c)+\beta \sum_{\theta_{t+1}} W_{n}^{m}\left(e^{\prime}\left(\theta^{t}, \theta_{t+1}\right)+b^{\prime}\left(\theta^{t}, \theta_{t+1}\right),\left(\theta^{t}, \theta_{t+1}\right)\right) \pi\left(\theta_{t+1} \mid \theta^{t}\right)\right\}
$$

subject to

$$
\begin{aligned}
c+\sum_{\theta_{t+1}} q\left(\theta^{t}, \theta_{t+1}\right) b\left(\theta^{t}, \theta_{t+1}\right) & =e_{n}^{m}\left(\theta^{t}\right)+b, \\
b\left(\theta^{t}, \theta_{t+1}\right) & \geq-\bar{B}_{n}^{m}\left(\theta^{t}, \theta_{t+1}\right)
\end{aligned}
$$


Our aim will be to find a sequence of solvency constraints for every agent that prevent default by not allowing agents to accumulate more debt than they would be willing to repay. At the same time, we do not want to set these constraints to be any tighter than needed. Following the spirit of Alvarez and Jermann, we will require that our solvency constraints bind if and only if the continuation utility of a country that is at its borrowing constraint equals the value to that country of defaulting. Note that such a constraint does not prevent a country from choosing to default, but requires that in equilibrium they have no incentive to do so. In states where they do not bind, we will set them at levels such that, were the constraints to bind, a country would be indifferent to default. However, in contrast to the closed economy considered by Alvarez and Jermann, there will be many ways in which these constraints can be set that satisfy this requirement. Hence we will augment the definition to require that intra-national risk sharing is as large as possible.

Definition 3 An equilibrium with solvency constraints that are minimally constraining is such that the solvency constraints satisfy, for all dates $t$ and all histories $\theta^{t}$

$$
\sum_{n=1}^{N} \phi_{n}^{m} W_{n}^{m}\left(-\bar{B}_{n}^{m}\left(\theta^{t-1}, \theta_{t}\right), \theta^{t}\right)=D^{m}\left(\theta^{t}\right)
$$

and such that for all $n, n^{\prime}$

$$
\phi_{n}^{m} \frac{\partial W_{n}^{m}\left(-\bar{B}_{n}^{m}\left(\theta^{t-1}, \theta_{t}\right), \theta^{t}\right)}{\partial b}=\phi_{n^{\prime}}^{m} \frac{\partial W_{n^{\prime}}^{m}\left(-\bar{B}_{n^{\prime}}^{m}\left(\theta^{t-1}, \theta_{t}\right), \theta^{t}\right)}{\partial b} .
$$

When solvency constraints are minimally constraining, they will bind if and only if the corresponding participation constraint in the planners problem binds. When these constraints bind, the marginal rates of substitution of all agents are not equalized across countries, although they are equalized within countries. Agents in constrained countries will accumulate assets according to their solvency constraints. In 
order to ensure that agents in unconstrained countries accumulate appropriately, it must be the case that equilibrium prices equal their marginal rate of substitution. This leads to our candidate equilibrium price sequence for bonds for all dates $t$ and histories $\theta^{t}$

$$
q\left(\theta^{t}, \theta_{t+1}\right) \equiv \max _{n, m}\left\{\beta \frac{u^{\prime}\left(c_{n}^{m}\left(\left(\theta^{t}, \theta_{t+1}\right)\right)\right)}{u^{\prime}\left(c_{n}^{m}\left(\theta^{t}\right)\right)} \pi\left(\theta_{t+1} \mid \theta^{t}\right)\right\} .
$$

Using these results, we are able to state a version of the second welfare theorem for our economy.

Proposition 4 Let $\left\{c_{n}^{m}\left(\theta^{t}\right)\right\}$ be an allocation that solves the planning problem above, and define Arrow and Arrow-Debreu prices by (4). Then if the value of this allocation at international is finite

$$
\sum_{t=0}^{\infty} \sum_{\theta^{t}} Q\left(\theta^{t} \mid \theta_{0}\right)\left(\sum_{m=1}^{M} \sum_{n=1}^{N} \lambda_{n}^{m} c_{n}^{m}\left(\theta^{t}\right)\right)<+\infty,
$$

there exists a sequence of solvency constraints $\left\{\bar{B}_{n}^{m}\left(\theta^{t}, \theta_{t+1}\right)\right\}$, an initial wealth allocation defined by $\left\{b_{n}^{m}\left(\theta^{0}\right)\right\}$, and a sequence of asset holdings $\left\{b_{n}^{m}\left(\theta^{t}, \theta_{t+1}\right)\right\}$ such that the plan $\left\{c_{n}^{m}\left(\theta^{t}\right), b_{n}^{m}\left(\theta^{t}, \theta_{t+1}\right)\right\}$ is a competitive equilibrium for the solvency constraints and initial wealth allocation. Moreover, the sequence of solvency constraints can be chosen so that they are minimally constraining.

Proof. The proof is constructive, and adapts that of Alvarez and Jermann (2) to our framework. Given an allocation $\left\{c_{n}^{m}\left(\theta^{t}\right)\right\}$ and the implied sequences of Arrow $\left\{q\left(\theta^{t}, \theta_{t+1}\right)\right\}$ and Arrow-Debreu $\left\{Q\left(\theta^{t} \mid \theta_{0}\right)\right\}$ prices, we can compute the bond holdings of an agent of type $n$ in country $m$ after history $\theta^{t}$ as the value of the difference between consumption and endowments from that history onwards. To do this, define $Q\left(\theta^{s} \mid \theta^{t}\right)$ as the history $\theta^{t}$ value of a unit of consumption in history $\theta^{s}$. Then

$$
b_{n}^{m}\left(\theta^{t}\right)=\left[c_{n}^{m}\left(\theta^{t}\right)-e_{n}^{m}\left(\theta^{t}\right)\right]+\sum_{s \geq 1} \sum_{\theta^{t+s}} Q\left(\theta^{s} \mid \theta^{t}\right)\left[c_{n}^{m}\left(\theta^{s+t}\right)-e_{n}^{m}\left(\theta^{s+t}\right)\right]
$$


where this sum is well defined by the assumption that implied interest rates are high. By construction of the Arrow prices, the sequences $\left\{c_{n}^{m}\left(\theta^{t}\right), b_{n}^{m}\left(\theta^{t}, \theta_{t+1}\right)\right\}$ satisfy the agents' flow budget constraints.

As an intermediate step, construct a first candidate sequence of solvency constraints $\widetilde{B}_{n}^{m}\left(\theta^{t}, \theta_{t+1}\right)$. For all histories $\theta^{t}$ such that the participation constraint of country $m$ binds, set $\widetilde{B}_{n}^{m}\left(\theta^{t}, \theta_{t+1}\right)=-b_{n}^{m}\left(\theta^{t}, \theta_{t+1}\right)$ for all agents in that country. For all other histories, we pick a candidate solvency constraint at such a level that, if it is satisfied, the agent cannot enjoy positive consumption in any future state. Specifically, pick

$$
\widetilde{B}_{n}^{m}\left(\theta^{t}, \theta_{t+1}\right)=-\sum_{s \geq 1} \sum_{\theta^{t+s}} Q\left(\theta^{s} \mid \theta^{t}\right) e_{n}^{m}\left(\theta^{s+t}\right)
$$

That $\left\{c_{n}^{m}\left(\theta^{t}\right), b_{n}^{m}\left(\theta^{t}, \theta_{t+1}\right)\right\}$ attains the maximum in the agents problem for prices $\left\{q\left(\theta^{t}, \theta_{t+1}\right)\right\}$ and solvency constraints $\left\{\widetilde{B}_{n}^{m}\left(\theta^{t}, \theta_{t+1}\right)\right\}$ can be verified by checking the necessary and sufficient Euler and transversality conditions for the agents problem. From the definition of Arrow prices in (4), we have that

$$
u^{\prime}\left(c_{n}^{m}\left(\theta^{t}\right)\right) q\left(\theta^{t}, \theta_{t+1}\right) \geq \beta u^{\prime}\left(c_{n}^{m}\left(\left(\theta^{t}, \theta_{t+1}\right)\right)\right) \pi\left(\theta_{t+1} \mid \theta^{t}\right)
$$

with equality if $-b_{n}^{m}\left(\theta^{t}, \theta_{t+1}\right)>-\widetilde{B}_{n}^{m}\left(\theta^{t}, \theta_{t+1}\right)$ which verifies that the Euler equation is satisfied. To see that the transversality condition holds, note that the requirement of high implied interest rates implies

$$
\lim _{T \rightarrow \infty} \sum_{\theta^{T}} Q\left(\theta^{T} \mid \theta_{0}\right) \sum_{s=1}^{\infty} \sum_{\theta^{s+T}} Q\left(\theta^{s+T} \mid \theta^{T}\right) e\left(\theta^{s+T}\right) .
$$

Therefore

$$
\begin{aligned}
& \lim _{T \rightarrow \infty} \sum_{\theta^{T}} \beta^{T} u^{\prime}\left(c_{n}^{m}\left(\theta^{T}\right)\right)\left[b_{n}^{m}\left(\theta^{T}\right)+\widetilde{B}_{n}^{m}\left(\theta^{T}\right)\right] \pi\left(\theta^{T} \mid \theta_{0}\right) \\
\leq & \lim _{T \rightarrow \infty} \sum_{\theta^{T}} \beta^{T} u^{\prime}\left(c_{n}^{m}\left(\theta^{T}\right)\right)\left[\sum_{s=1}^{\infty} \sum_{\theta^{s+T}} Q\left(\theta^{s+T} \mid \theta^{T}\right) c_{n}^{m}\left(\theta^{s+T}\right)\right] \pi\left(\theta^{T} \mid \theta_{0}\right),
\end{aligned}
$$


from the fact that $b_{n}^{m}\left(\theta^{T}\right)+\widetilde{B}_{n}^{m}\left(\theta^{T}\right)=0$ if the participation constraint for country $m$ binds at $\theta^{T}$, or equals $\sum_{s=1}^{\infty} \sum_{\theta^{s+T}} Q\left(\theta^{s+T} \mid \theta^{T}\right) c_{n}^{m}\left(\theta^{s+T}\right) \geq 0$, by construction of our candidate solvency constraints, otherwise. But as the allocation is feasible we have

$$
\begin{aligned}
& \lim _{T \rightarrow \infty} \sum_{\theta^{T}} \beta^{T} u^{\prime}\left(c_{n}^{m}\left(\theta^{T}\right)\right)\left[\sum_{s=1}^{\infty} \sum_{\theta^{s+T}} Q\left(\theta^{s+T} \mid \theta^{T}\right) c_{n}^{m}\left(\theta^{s+T}\right)\right] \pi\left(\theta^{T} \mid \theta_{0}\right) \\
\leq & \lim _{T \rightarrow \infty} \sum_{\theta^{T}} \beta^{T} u^{\prime}\left(c_{n}^{m}\left(\theta^{T}\right)\right)\left[\sum_{s=1}^{\infty} \sum_{\theta^{s+T}} Q\left(\theta^{s+T} \mid \theta^{T}\right) e\left(\theta^{s+T}\right)\right] \pi\left(\theta^{T} \mid \theta_{0}\right) \\
\leq & u^{\prime}\left(c_{n}^{m}\left(\theta_{0}\right)\right) \lim _{T \rightarrow \infty} \sum_{\theta^{T}} Q\left(\theta^{T} \mid \theta_{0}\right) \sum_{s=1}^{\infty} \sum_{\theta^{s+T}} Q\left(\theta^{s+T} \mid \theta^{T}\right) e\left(\theta^{s+T}\right)=0,
\end{aligned}
$$

where the last inequality follows from the definition of the Arrow-Debreu and Arrow prices, and the last equality follows from above.

Finally, to show that we can set these solvency constraints so that they are minimally constraining, define the value functions $\left\{W_{n}^{m}\right\}$ that solve the agents problem for all $n$ and $m$. As the plan $\left\{c_{n}^{m}\left(\theta^{t}\right), b_{n}^{m}\left(\theta^{t}, \theta_{t+1}\right)\right\}$ satisfies the Euler and transversality conditions, it constitutes a solution for these value functions as long as the initial conditions are given by $\left\{b_{n}^{m}\left(\theta^{0}\right)\right\}$. For all $\theta^{t}$ such that the participation constraint of country $m$ binds, define our final sequence of solvency constraints $\left\{\bar{B}_{n}^{m}\left(\theta^{t}, \theta_{t+1}\right)\right\}$ such that $\bar{B}_{n}^{m}\left(\theta^{t}, \theta_{t+1}\right)=\widetilde{B}_{n}^{m}\left(\theta^{t}, \theta_{t+1}\right)$. For all other $\theta^{t}$, define them such that

$$
\sum_{n=1}^{N} \phi_{n}^{m} W_{n}^{m}\left(-\bar{B}_{n}^{m}\left(\theta^{t-1}, \theta_{t}\right), \theta^{t}\right)=D^{m}\left(\theta^{t}\right)
$$

and

$$
\phi_{n}^{m} \frac{\partial W_{n}^{m}\left(-\bar{B}_{n}^{m}\left(\theta^{t-1}, \theta_{t}\right), \theta^{t}\right)}{\partial b}=\phi_{n^{\prime}}^{m} \frac{\partial W_{n^{\prime}}^{m}\left(-\bar{B}_{n^{\prime}}^{m}\left(\theta^{t-1}, \theta_{t}\right), \theta^{t}\right)}{\partial b} .
$$

Using the envelope condition, it is easy to verify that this latter condition is also satisfied at states at which the participation constraint binds.

This framework has two desirable features. First, individual residents retain access to international financial markets, and it is to these markets that the burden of 
ensuring that default does not occur is devolved. Second, the decentralization does not rule out the possibility of default: default remains feasible. However, default does not occur because the solvency constraints leave agents with no incentive to default.

However, there are two obvious criticisms of this approach. First, there is a sense in which the burden of ruling out default that has been placed upon financial markets is very large. As countries must have no incentive to default, in setting these solvency constraints it is necessary for financial markets to have knowledge of the preferences of a nations government, which in turn depends upon the preferences of its residents and the vector of national Pareto weights. Similarly, financial markets must have knowledge of the aggregate endowment process of a nation, as it is this process that determined the worst that can happen to a country in default.

Second, and in contrast to the closed economy model, the individual solvency constraints can take unappealing forms. Note that complete markets within a country serve to ensure that marginal rates of substitution are equalized within a country. Hence, when one agent is borrowing constrained, all agents must be constrained. In general, the asset positions of agents will depend upon their initial wealth levels, and at any moment in time some agents within a country may be creditors even when a nation as a whole is a debtor. Consequently, it may be necessary that for some types $B_{n}^{m}$ be negative so that some agents are constrained to save a minimum amount in bonds. In Section ?? below we present a simple numerical example which serves to illustrate this criticism.

In summary, we have shown that when domestic courts enforce contracts symmetrically between both residents and foreigners, it is possible to decentralize the constrained efficient allocations in an economy in which individuals borrow subject to their own solvency constraint. These constraints do not rule out default, but make it suboptimal for the government in equilibrium. In the next section we consider the 
alternative case in which domestic courts do not enforce contracts with foreigners and residents can individually default.

\section{RESIDENT DEFAULT RISK}

\section{Competitive Equilibrium}

Consider a world economy in which there are $M+1$ sets of state contingent securities. The first $M$ of these securities are country specific trading only within country $m$ while the last refers to securities traded on world markets. We denote the prices of these one-period securities as $q\left(\theta^{t}, \theta_{t+1}\right)$ for international securities purchased after history $\theta^{t}$ for payment in period $t+1$ after observing event $\theta_{t+1}$, and, analogously for securities in country $m$, by $p^{m}\left(\theta^{t}, \theta_{t+1}\right)$. Corresponding period-zero dated security prices are given recursively by

$$
P^{m}\left(\theta^{s}\right)=P^{m}\left(\theta^{s-1}\right) p^{m}\left(\theta^{s-1}, \theta_{s}\right), \text { for all } m \text { and } Q\left(\theta^{s}\right)=Q\left(\theta^{s-1}\right) q\left(\theta^{s-1}, \theta_{s}\right) .
$$

Holdings of foreign securities are denoted $f\left(\theta^{t}, \theta_{t+1}\right)$ and of domestic securities in country $m$, by $b^{m}\left(\theta^{t}, \theta_{t+1}\right)$.

It is assumed that an agent that defaults does so assuming that prices in domestic markets stay unchanged resulting from the fact that they are small relative to the market. Given a domestic price vector $p^{m}$ the problem of an agent that defaults at a given point in time $s$ after history $\theta^{s}$ with domestic bond holdings $b$ is represented as

$$
\begin{aligned}
D_{n}^{m}\left(b, \theta^{s},\left\{p^{m}\right\}\right)= & \max _{c,\left\{b^{\prime}\right\}} \sum_{t=s}^{\infty} \beta^{t-s} \sum_{\theta^{t} \mid \theta^{s}} \pi\left(\theta^{t} \mid \theta^{s}\right) U_{n}^{m}\left(c\left(\theta^{t}\right)\right), \\
\text { subject to } \quad & c+\sum_{\theta_{t+1}} p^{m}\left(\theta^{t}, \theta_{t+1}\right) b\left(\theta^{t}, \theta_{t+1}\right)=e\left(\theta^{t}\right)+b, \\
& b\left(\theta^{t}, \theta_{t+1}\right) \geq-\bar{B},
\end{aligned}
$$


for all $\theta^{t}$ that continue $\theta^{s}$ with $b$ given, and where in the last constraint $\bar{B}$ is set sufficiently large so that it never binds, and serves to rule out Ponzi schemes.

The value $D_{n}^{m}\left(b, \theta^{t},\left\{p^{m}\right\}\right)$ plays an important role in determining the set of selfenforcing allocations. Specifically, the residents problem (RP) is to choose sequences for consumption and domestic and international securities holdings to maximize

$$
\sum_{t=0}^{\infty} \beta^{t} \sum_{\theta^{t}} \pi\left(\theta^{t}\right) U_{n}^{m}\left(c\left(\theta^{t}\right)\right),
$$

subject to

$$
\begin{aligned}
& c\left(\theta^{t}\right)+\sum_{\theta_{t+1}} q\left(\theta^{t}, \theta_{t+1}\right) f\left(\theta^{t}, \theta_{t+1}\right)+\sum_{\theta_{t+1}} p^{m}\left(\theta^{t}, \theta_{t+1}\right) b\left(\theta^{t}, \theta_{t+1}\right) \\
\leq & e\left(\theta^{t}\right)+f\left(\theta^{t-1}, \theta_{t}\right)+b\left(\theta^{t-1}, \theta_{t}\right),
\end{aligned}
$$

for all $\theta^{t}=\left(\theta^{t-1}, \theta_{t}\right)$ for all $t$,

$$
\sum_{t=s}^{\infty} \beta^{t-s} \sum_{\theta^{t} \mid \theta^{s}} \pi\left(\theta^{t} \mid \theta^{s}\right) U_{n}^{m}\left(c\left(\theta^{t}\right)\right) \geq D_{n}^{m}\left(b\left(\theta^{s-1}, \theta_{s}\right), \theta^{s},\left\{p^{m}\right\}\right),
$$

for all $\theta^{s}$, for all $s$, and

$$
b\left(\theta^{t}, \theta_{t+1}\right) \geq-\bar{B}, \quad f\left(\theta^{t}, \theta_{t+1}\right) \geq-\bar{F} .
$$

for all $\theta^{t}$ for all $t$, and $b\left(\theta^{0}\right)$ given Here, (5) is the usual flow budget constraint, and (6) is the participation constraint which guarantees that a resident cannot choose a path for consumption that would leave them preferring to default after any history $\theta^{s}$. The final constraints (7) serve to rule out Ponzi schemes in both the domestic and foreign bonds. Note that (6) assumes that default is not feasible, which is much stronger than the framework of the previous section in which it is feasible, but never optimal, for an agent to default. Note also that, given the preferences of the national government, the vector of initial domestic securities holdings is assumed to be chosen to maximize the governments objectives. 
In this framework, we allow the domestic and international state contingent securities to trade at different prices. This is despite the fact that such securities have the same payoffs and are free of default risk (domestic securities by virtue of domestic enforcement mechanisms, and international by virtue of the infeasibility of default implied by constraint (6)). Indeed, it will emerge that unless the interest rate on domestic borrowing is higher than that on international borrowing, there is no effective penalty for default. Arbitrage opportunities are ruled out by the participation constraint (6).

This leads to the definition of an equilibrium in this economy. To distinguish it from the equilibrium with solvency constraints above, we follow Kehoe and Levine (11) and refer to it as a debt constrained equilibrium.

Definition 5 A debt constrained equilibrium is an allocation $\left\{c_{n}^{m}\left(\theta^{t}\right), b_{n}^{m}\left(\theta^{t}, \theta_{t+1}\right)\right.$, $\left.f_{n}^{m}\left(\theta^{t}, \theta_{t+1}\right)\right\}$, and a price system $\left\{q\left(\theta^{t}, \theta_{t+1}\right), p^{m}\left(\theta^{t}, \theta_{t+1}\right)\right\}$ for all countries $m$, such that for all countries $m$ and types $n$, the allocation solves the residents problem given the price system and initial asset holdings, and markets clear:

$$
\begin{array}{ll}
\sum_{m=1}^{M} \sum_{n=1}^{N} \lambda_{n}^{m} c_{n}^{m}\left(\theta^{t}\right) \leq \sum_{m=1}^{M} \sum_{n=1}^{N} \lambda_{n}^{m} e_{n}^{m}\left(\theta^{t}\right), & \text { for all dates } t \text { and all histories } \theta^{t} \\
\sum_{n=1}^{N} \lambda_{n}^{m} b_{n}^{m}\left(\theta^{t}, \theta_{t+1}\right)=0, & \text { for all } \theta_{t+1} \text { and all } m, \\
\sum_{m=1}^{M} \sum_{n=1}^{N} \lambda_{n}^{m} f_{n}^{m}\left(\theta^{t}, \theta_{t+1}\right)=0 . & \text { for all } \theta_{t+1} .
\end{array}
$$

The characterization of this equilibrium is inhibited by the fact that the consumption set of a resident is not convex. This follows from the fact that $D_{n}^{m}\left(b, \theta^{s},\left\{p^{m}\right\}\right)$ is typically strictly concave in $b$ for all $\theta^{s}$ and $\left\{p^{m}\right\}$. Jeske (9) shows how this problem can be surmounted. For a resident of type $n$ in country $m$, the transfer they make to foreigners after any history $\theta^{s}$ is equal to

$$
n x_{n}^{m}\left(\theta^{s}\right)=\sum_{\theta_{s+1}} q\left(\theta^{s}, \theta_{s+1}\right) f_{n}^{m}\left(\theta^{s}, \theta_{s+1}\right)-f_{n}^{m}\left(\theta^{s}\right)
$$


which we denote by $n x_{n}^{m}\left(\theta^{s}\right)$ as the net exports of a resident of type $n$.

Clearly, if the value of the future stream of such transfers, evaluated at domestic prices, was positive, a resident would be better off by defaulting on their debts. That is, a necessary condition for repayment is that foreign bond holdings satisfy

$$
\sum_{\theta^{s} \geq \theta^{t}} P^{m}\left(\theta^{s}\right) n x_{n}^{m}\left(\theta^{s}\right) \leq 0
$$

for all histories $\theta^{t}$, where the notation $\theta^{s} \geq \theta^{t}$ is used to denote that the summation is over all histories that continue $\theta^{t}$. Note that this constraint defines a convex subset of the set of affordable allocations. Jeske ((9) Propositions 3 and 4) showed that the solution to an auxiliary residents problem, which is simply problem (PP) modified in that the sequence of participation constraints (6) is replaced by the sequence in (8), is also the solution to the original problem.

As domestic markets are complete and domestic contracts are enforceable, in equilibrium we have

$$
p^{m}\left(\theta^{t-1}, \theta_{t}\right)=\beta \pi\left(\theta_{t} \mid \theta_{t-1}\right) \frac{U_{n}^{m \prime}\left(c\left(\theta^{t-1}, \theta_{t}\right)\right)}{U_{n}^{m \prime}\left(c\left(\theta^{t-1}\right)\right)},
$$

for all $n$. That is, all residents of a country have the same marginal rate of substitution. This also implies that, in any state of the world $\theta^{t}$, either all residents are on their participation constraints (6) or none are constrained. The intuition is that, if some residents were constrained while others were not, the unconstrained residents could borrow from international markets and lend to the constrained residents. In this sense, we can refer to a country as a whole as being either constrained or unconstrained. Further, if a country $m$ is unconstrained, it must be that the international bond price equals the marginal rate of substitution of all residents in that country. If the residents of a country are constrained, they would like to borrow more, and their marginal rates of substitution must be lower than this price. This implies that

$$
q\left(\theta^{t-1}, \theta_{t}\right)=\max _{m=1, \ldots, M} p^{m}\left(\theta^{t-1}, \theta_{t}\right)
$$


That is, domestic interest rates are always at least as high as international interest rates. It is this fact that acts as a deterrent to default; a resident who defaults would only have access to a market in which interest rates are higher in the periods in which an individual wants to borrow.

In our analysis so far, we have concentrated solely on the residents decision to default. A natural question that arises is whether it is possible for residents to voluntarily enter into agreements that their government would like to repudiate? As agents cannot coordinate in default, is it possible that they could receive allocations worse than autarky in some states of the world? The following proposition shows that this is never the case.

Proposition 6 In the debt constrained equilibrium, the $\left\{\phi_{n}^{m}\right\}$-weighted average of residents utilities, in the continuation of the allocation after any history $\theta^{t}$, is always no less than $D^{m}\left(\theta^{t}, \phi^{m}\right)$.

Proof. We show the result for $t=0$; the argument is analogous after any other history. As the government is able to set transfer to maximize the weighted average of residents utilities, the weighted average of residents utilities in country $m$ can be written as the solution to the problem

$$
\max _{c^{m}} \sum_{n=1}^{N} \phi_{n}^{m} \sum_{t=0}^{\infty} \beta^{t} \sum_{\theta^{t}} \pi\left(\theta^{t}\right) U_{n}^{m}\left(c_{n}^{m}\left(\theta^{t}\right)\right)
$$

subject to the date zero budget constraint

$$
\sum_{t=0}^{\infty} \sum_{\theta^{t}} P^{m}\left(\theta^{t}\right) \sum_{n=1}^{N} c_{n}^{m}\left(\theta^{t}\right) \leq \sum_{t=0}^{\infty} \sum_{\theta^{t}} P^{m}\left(\theta^{t}\right) \sum_{n=1}^{N}\left[e_{n}^{m}\left(\theta^{t}\right)-n x_{n}^{m}\left(\theta^{t}\right)\right],
$$

given sequences of prices and net exports. By the result at (8) above the autarky allocation is affordable at these prices, but as it was not chosen it cannot yield a greater value for $\left\{\phi_{n}^{m}\right\}$-weighted resident utility. 
The debt constrained allocations are resource feasible and, by the result of Proposition 6 , satisfy the national participation constraints. Hence they are no better than the constrained efficient allocation. It is also straightforward to produce examples, such as the one examined in Section ??, in which the debt constrained equilibrium is strictly worse than the constrained efficient equilibrium. This opens up the possibility for Pareto improving government intervention. The obvious remedy is for the government to reform the domestic law enforcement system to allow domestic residents to commit to honoring contracts with foreigners. However, in practice such reform may not be possible. Current efforts at reducing corruption in the developing world, of which removing partiality towards domestic residents in judicial systems is one part, have run into a number of difficulties. However, while national governments are often unable to effect reform of domestic institutions, they typically retain control over their borders, and hence also over flows of capital. Could capital controls be welfare improving? We show in the next subsection that capital flows subsidies, not capital controls, can be used to effect a Pareto improvement.

\section{Efficient Borrowing Subsidies}

Consider the constrained efficient allocation $\left\{c_{n}^{m}\left(\theta^{t}\right)\right\}_{n, m, \theta^{t}, t}$ constructed in Section ?? above. Given this allocation, we can construct sequences of domestic and international bond prices using the formulae (9) and (10). By the results above, we know that this allocation evaluated at these prices will in general violate the sequence of participation constraints (8). Moreover, the equality of marginal rates of substitution over residents of a country implies that this constraint will be violated for all residents of a country at the same time. Knowledge of the allocation also allows us to calculate the contribution of each type to net exports, as $n x_{n}^{m}\left(\theta^{t}\right)=e_{n}^{m}\left(\theta^{t}\right)-c_{n}^{m}\left(\theta^{t}\right)$, which given an international price for bonds in this new equilibrium $q\left(\theta^{t}, \theta_{t+1}\right)$ (which will 
in general differ from the $q$ calculated from equation (10)), implies asset holdings of

$$
n x_{n}^{m}\left(\theta^{t}\right)=\sum_{\theta_{t+1}} q\left(\theta^{t}, \theta_{t+1}\right) f_{n}^{m}\left(\theta^{t}, \theta_{t+1}\right)-f_{n}^{m}\left(\theta^{t}\right) .
$$

Our approach will be to introduce a subsidy on international lending so that the rents gained from access to international markets are larger, and the penalties from being excluded are greater. Attaching the subsidy to new lending is notationally simpler, but equivalent to, a policy of subsidizing a residents interest payments on past borrowing.

In order to introduce such a subsidy, it will be necessary to distinguish between before-tax and after-tax international bond prices. Specifically, denote by $q^{m}\left(\theta^{t}, \theta_{t+1}\right)$, the price of an international state contingent security, after taxes and subsidies, in country $m$. This will be determined by the international price $q\left(\theta^{t}, \theta_{t+1}\right)$ and any tax (or subsidy if negative) $\tau^{m}\left(\theta^{t}, \theta_{t+1}\right)$, according to

$$
q^{m}\left(\theta^{t}, \theta_{t+1}\right)=\left(1+\tau^{m}\left(\theta^{t}, \theta_{t+1}\right)\right) q\left(\theta^{t}, \theta_{t+1}\right)
$$

where for the moment we are allowing this subsidy to be country specific. A government policy is then a sequence of taxes and subsidies on foreign lending $\tau^{m}\left(\theta^{t}\right)$, and a sequence of lump-sum taxes $T_{n}^{m}\left(\theta^{t}\right)$, which for the moment we allow to be resident specific.

Our task is, given a consumption allocation, to find a government policy and a sequence of before-tax prices $\left\{q\left(\theta^{t}, \theta_{t+1}\right)\right\}$ such that the implied securities holdings can be supported in a debt-constrained equilibrium. This leads to the following definition.

Definition 7 A debt constrained equilibrium with taxes is an allocation $\left\{c_{n}^{m}\left(\theta^{t}\right)\right.$, $\left.b_{n}^{m}\left(\theta^{t}, \theta_{t+1}\right), f_{n}^{m}\left(\theta^{t}, \theta_{t+1}\right)\right\}$, a government policy $\left\{\tau^{m}\left(\theta^{t}\right), T_{n}^{m}\left(\theta^{t}\right)\right\}$, and a price system for international bonds $\left\{q\left(\theta^{t}, \theta_{t+1}\right)\right\}$, and domestic bonds $\left\{p^{m}\left(\theta^{t}, \theta_{t+1}\right)\right\}$ for 
all countries $m$, such that for all countries $m$ and types $n$, the allocation solves the residents problem given the price system, government policy and initial asset holdings, each government's budget balances,

$$
\sum_{t=0}^{\infty} \sum_{\theta^{t}} \sum_{n=1}^{N} P\left(\theta^{t}\right)\left[\tau^{m}\left(\theta^{t}\right) \widehat{q}\left(\theta^{t}, \theta_{t+1}\right) f_{n}^{m}\left(\theta^{t}, \theta_{t+1}\right)-T_{n}^{m}\left(\theta^{t}\right)\right]=0
$$

and markets clear:

$$
\begin{array}{ll}
\sum_{m=1}^{M} \sum_{n=1}^{N} \lambda_{n}^{m} c_{n}^{m}\left(\theta^{t}\right) \leq \sum_{m=1}^{M} \sum_{n=1}^{N} \lambda_{n}^{m} e_{n}^{m}\left(\theta^{t}\right), & \text { for all dates } t \text { and all histories } \theta^{t} \\
\sum_{n=1}^{N} \lambda_{n}^{m} b_{n}^{m}\left(\theta^{t}, \theta_{t+1}\right)=0, & \text { for all } \theta_{t+1} \text { and all } m, \\
\sum_{m=1}^{M} \sum_{n=1}^{N} \lambda_{n}^{m} f_{n}^{m}\left(\theta^{t}, \theta_{t+1}\right)=0 . & \text { for all } \theta_{t+1} .
\end{array}
$$

The following proposition establishes the main result of this section.

Proposition 8 If implied international interest rates are high, any constrained efficient consumption allocation $\left\{c_{n}^{m}\left(\theta^{t}\right)\right\}$ can be supported as a debt constrained equilibrium with taxes.

Proof. The proof is constructive. Given an allocation, and a first estimate of prices from (9) and (10), we can check whether at the efficient allocation a residents participation constraint is satisfied. Let $H$ be the (countable) set of all possible histories $\theta^{t}$, and let $N V^{m}$ be that subset of $H$, such that for all $\theta^{t} \in N V^{m}$ no country $m$ residents participation constraints are violated at $\theta^{t}$. For all $\theta^{t} \in N V^{m}$ set the after tax international prices $q^{m}\left(\theta^{t}, \theta_{t+1}\right)=q\left(\theta^{t}, \theta_{t+1}\right)$ so that for all $m, \tau^{m}\left(\theta^{t}\right)=0$.

Given the efficient allocation, we can form net exports for a country after any history as $n x^{m}\left(\theta^{t}\right)=e^{m}\left(\theta^{t}\right)-c^{m}\left(\theta^{t}\right)$. For all $\theta^{t} \in H \backslash N V^{m}$, we can use these values to construct an estimate of the extent to which a country as a whole is violating its participation constraint (noting that if some residents of a country have violated their 
constraints, then all residents of that country have, and we can without loss focus on country aggregates)

$$
-\sum_{\theta^{s} \geq \theta^{t}} P^{m}\left(\theta^{s}\right) n x^{m}\left(\theta^{s}\right)
$$

which are negative (as the constraints are violated) and finite if international interest rates are high $\left(\right.$ as $\left.P^{m}\left(\theta^{t}\right) \leq Q\left(\theta^{t}\right)\right)$. Note that this implies that the amount by which the constraints are violated is bounded above by zero, and below by the finite present value of the country's endowment.

In equilibrium, at the world pre-tax bond price, we have

$$
n x^{m}\left(\theta^{t}\right)=\sum_{\theta_{t+1}} q\left(\theta^{t}, \theta_{t+1}\right) f^{m}\left(\theta^{t}, \theta_{t+1}\right)-f^{m}\left(\theta^{t}\right) .
$$

Our aim is to find a sequence of values for extra surplus $S^{m}\left(\theta^{t}\right) \geq 0$ for each country and each $\theta^{t} \in H \backslash N B$ for which its participation constraints are violated, such that when the surplus is added, these participation constraints are then satisfied. In equilibrium, we will distribute this surplus in terms of a subsidy on lending, so that

$$
S^{m}\left(\theta^{t}\right)=-\tau\left(\theta^{t}\right) \sum_{\theta_{t+1}} q\left(\theta^{t}, \theta_{t+1}\right) f^{m}\left(\theta^{t}, \theta_{t+1}\right)
$$

(where if $\tau<0$ we have a subsidy). This is a countable sequence of affine equations in a countable number of unknowns which we can index by $j$. It is convenient to view this as a mapping from the closed $e$ ball in $l_{\infty}$ into itself, where $e$ is defined as the largest possible value of the aggregate endowment. Then, as the Arrow-Debreu prices are absolutely summable, the mapping is a bijection and there is a unique solution for the surplus sequence.

Given initial asset holdings, we can then solve for future asset holdings by iterating on the following. Given $f^{m}\left(\theta^{t}\right)$, we can find $f^{m}\left(\theta^{t}, \theta_{t+1}\right)$ from, for countries whose 
constraints bind at $\theta^{t}$

$$
\begin{aligned}
n x^{m}\left(\theta^{t}\right)-S^{m}\left(\theta^{t}\right) & =\left(1+\tau^{m}\left(\theta^{t}\right)\right) \sum_{\theta_{t+1}} q\left(\theta^{t}, \theta_{t+1}\right) f^{m}\left(\theta^{t}, \theta_{t+1}\right)-f^{m}\left(\theta^{t}\right) \\
& =\sum_{\theta_{t+1}} q^{m}\left(\theta^{t}, \theta_{t+1}\right) f^{m}\left(\theta^{t}, \theta_{t+1}\right)-f^{m}\left(\theta^{t}\right)
\end{aligned}
$$

where $q^{m}\left(\theta^{t}, \theta_{t+1}\right)$ is the level of after-tax international bond prices in country $m$. Given estimates of bond holdings for countries whose constraints are binding at $\theta^{t}$, we can construct the aggregate holdings for countries whose constraints are not binding from the market clearing condition. If the set of such countries at $\theta^{t}$ is given by $M\left(\theta^{t}\right)$, as these countries set no subsidy, and trade at $q\left(\theta^{t}, \theta_{t+1}\right)$, we can use

$$
\sum_{m \in M\left(\theta^{t}\right)} n x^{m}\left(\theta^{t}\right)=\sum_{m \in M\left(\theta^{t}\right)}\left[\sum_{\theta_{t+1}} q\left(\theta^{t}, \theta_{t+1}\right) f^{m}\left(\theta^{t}, \theta_{t+1}\right)-f^{m}\left(\theta^{t}\right)\right],
$$

to get an estimate of the $q\left(\theta^{t}, \theta_{t+1}\right)$ (and hence $\left.\tau\left(\theta^{t}\right)\right)$ where we have noted that $\tau\left(\theta^{t}\right)$ is common over all assets at this history, and all countries whose constraints bind.

The precise sequence of lump-sum taxes across residents is indeterminate. However, its present value, along with initial domestic bond transfers, can be determined from residents lifetime budget constraints.

In Section ?? below, in the context of a simple numerical example that can be computed by hand, we show how to construct such a government policy. That example is tractable because it exploits symmetry over agents and stationarity over time to simplify the construction of the optimal sequence of subsidies. More generally, the following method, which relies on the fact that interest rates are high and hence histories that are distant in time are significantly discounted, appears to work well in practice. For each $n=1,2,3, \ldots$, set all but the first $n$ elements of the surplus sequence to zero, and solve the first $n$ equations for the participation constraint. By 
construction, these equations are linearly independent, and have a unique solution. Repeating for each $n$ gives us, for each $j$, a monotone decreasing sequence of values that are bounded below by zero and hence converge. This is our $\left\{S^{m}\left(\theta^{t}\right)\right\}$ for all $\theta^{t} \in H \backslash N B$.

\section{AN ILLUSTRATIVE EXAMPLE}

Consider the following example which can be solved by hand. There are two agents each with identical logarithmic felicity functions. There are two states of the world $\theta=1,2$, with type $\theta$ agents receiving the high endowment $1+y$ for some $y \in(0,1)$ when the state is $\theta$, and the low endowment $1-y$ otherwise. The initial state of the world determined by a coin flip, after which it alternates deterministically, or $\pi(2 \mid 1)=\pi(1 \mid 2)=1$. The total population of each country is normalized to one, and total measure of each type throughout the world is set to one, so that the world endowment is fixed at two for all periods in all states. However, the distribution of each type within each country varies, with type one agents being of measure $1-\omega$ in country one for some $\omega<1 / 2$. The aggregate endowment of country one is $e^{1}(1)=1+y(1-2 \omega)>1$ in state one and $e^{1}(2)=1-y(1-2 \omega)<1$ in state two meaning that state one is the "good state" for country one.

When nations, but not individual residents, default we can solve for efficient allocations using a completely standard limited commitment model. Restricting attention to the symmetric stationary efficient allocation, consumption alternates between $1+x$ and $1-x$ where

$$
x=\min _{z \geq 0}\{\log (1+z)+\beta \log (1-z) \geq \log (1+y(1-2 \omega))+\beta \log (1-y(1-2 \omega))\} .
$$

The critical values of $\beta$ are give by

$$
\beta_{F I} \equiv-\frac{\log (1+y(1-2 \omega))}{\log (1-y(1-2 \omega))}, \quad \text { and } \quad \beta_{A} \equiv \frac{1-y(1-2 \omega)}{1+y(1-2 \omega)} \text {. }
$$


If $\beta \geq \beta_{F I}$, the solution to this problem is $x=0$ and full insurance is achievable. If $\beta \leq \beta_{A}$, the expression $\log (1+z)+\beta \log (1-z)$ reaches a maximum at $z=y$ and only autarky is feasible.

To determine aggregate capital flows, note that world interest rates are determined by the marginal rate of substitution of the country that is unconstrained tomorrow. Then we must have $q=\beta(1+x) /(1-x)>\beta$, and so world interest rates are lower than under complete markets. To determine the borrowing constraints on nations consistent with this allocation, the country budget constraints combined with symmetry and stationarity over time give $f^{*}=(y(1-2 \omega)-x) /(1+q)$. Hence, the solvency constraints for countries expecting the high shock next period must be set to this $f^{*}$.

To see how these allocations can be decentralized, note that in the stationary allocation individual bond holdings must satisfy $f_{t}^{i}=\left(e_{t}^{i}-c_{t}^{i}\right) /(1+q)$. In general, this will be positive for types with the high endowment and negative for types with the low endowment. However, the solvency constraints will bind for all types at the same dates. Consequently, these solvency constraints will enforce minimum positive holdings of these assets for some agents. This illustrates our second criticism of this decentralization.

We now consider the case in which enforcement institutions discriminate in favor of domestic residents. To characterize the debt constrained allocations, once again we will focus on symmetric allocations, and in the light of Proposition 6, we will consider the case in which $\beta>\beta_{A}$. Summing the budget constraints of individuals starting from a date in which the country has the high shock, we get

$$
\frac{1+x^{m}+q\left(1-x^{m}\right)}{1-p q} \leq \frac{1+y(1-2 \omega)+q(1-y(1-2 \omega))}{1-p q}+\frac{f-q f^{\prime}+q\left(f^{\prime}-q f\right)}{1-p q}
$$

where $f$ denotes bond holdings that pay off in the high state, and $f^{\prime}$ bonds that pay off in the low state. The last term, which represents the rents earned from access 
to international markets, must be zero as the participation constraint (8) binds in the high state. Rearranging this, and substituting for the value of net exports, we get $x^{m}(1-q)=y(1-2 \omega)(1-q)$. There are two solutions to this equation. The first is autarky, or $x^{m}=y(1-2 \omega)$, while the second requires $q=1$. Substituting this into the expression for $q$ we get $x^{m}=(1-\beta) /(1+\beta)$, and $p=\beta^{2}$, and note that $x^{m}<y(1-2 \omega)$ as long as $\beta>\beta_{A}$. International interest rates are zero so that international debt is a bubble asset; it is a similar mechanism that generates the existence of debt in Hellwig and Lorenzoni (8). Domestic interest rates are positive, which provides enough surplus from the access to international financial markets to deter default. Exploitation of the apparent arbitrage opportunity is prevented by the existence of the debt constraints.

Under symmetry, the (absolute value) of trade at any point in time is equal to $y(1-2 \omega)-x^{m}$, which given that $q=1$ implies that the level of bond trade is equal to $\left(y(1-2 \omega)-x^{m}\right) / 2$. Note that this is due to the assumption of symmetry; equivalent allocations could have been obtained by trading a non-interest paying token of value $y(1-2 \omega)-x^{m}$ in each period. This equivalence highlights the similarity of these allocations to those derived from the turnpike monetary model of Townsend (13). And as in that model, the payment of interest on this token, or in our case the subsidization of capital flows, can lead to a welfare improvement.

To see how capital flow subsidies can implement the constrained efficient allocation (in the symmetric case, parameterized by $x$ ), note that in such a world, agents in countries that are unconstrained at time $t$ must face domestic and international interest rates that are equal to $p^{U}=q=\beta(1+x) /(1-x)$. When a country is constrained, the domestic interest rate is determined by $p^{C}=\beta(1-x) /(1+x)<p^{U}$ and so is higher than the international interest rate. Starting from any period, we can then calculate the time-zero domestic prices $P_{t}$ as described above.

The relevant participation constraint for an agent, starting in a period denoted by 
0 in which it binds, is given by

$$
0=P_{0} f_{0}-P_{0} q_{1} f_{1}+P_{1} f_{1}-P_{1} q_{2} f_{2}+P_{2} f_{2}-\ldots
$$

As the agent is not constrained in period one, $P_{1}=P_{0} p^{U}=P_{0} q$, while as the agent is constrained in period two we have that all the terms starting with $P_{2} f_{2}$ onwards sum to zero. Hence we have $0=P_{0} f_{0}-P_{0} q \hat{q} f_{2}$, where $\hat{q}$ denotes the after tax or subsidy price of an international bond in a period where the agents are constrained. Dividing by $P_{0}$ and imposing $f_{0}=f_{2}$ by symmetry we get $\hat{q}=1 / q$, which is greater than one. This is equivalent to a borrowing subsidy because it occurs in periods in which the consumer is borrowing, or selling bonds: for a given amount of repayment tomorrow, the consumer is able to borrow a greater amount today. In fact, because the after subsidy price of these bonds in the home country is greater than one, it is as though the interest rate on borrowing is negative. As a result, the agent would like to borrow more, but is borrowing constrained.

\section{CONCLUSION}

The shift in emerging market capital flows away from sovereign towards private borrowers has led to much speculation about changes in the pattern of future capital flows, their efficiency, and the likelihood of future debt repudiations. Some authors have used this shift to justify the imposition of capital controls. In this paper we have shown that, although the efficiency and level of private capital flows depends on the enforcement institutions of a country and the extent to which they discriminate between domestic residents and foreigners in the enforcement of contracts, capital controls are never justified. If enforcement is symmetric, private capital flows are constrained efficient and no government intervention is necessary. If, however, enforcement favors domestic residents, private capital flows will tend to be inefficiently 
low, but it is a subsidy on capital flows that promotes efficiency by increasing the benefit to accessing international markets and thus increasing the penalty associated with exclusion from these markets.

A subsidy on capital flows may also be preferable to alternative schemes on the basis of the information required by the government: the government need not know the identity of the borrower or whether they have defaulted. Nonetheless, the information requirements for a subsidy are large. In the present perfect information environment, it is impossible to definitively investigate the superiority of a particular scheme in this regard. To investigate the optimal regulation of capital flows in a private information environment will require further work on the decentralization of optimal allocations with imperfect information.

\section{REFERENCES}

[1] Al-Kilani, F. (1999). Corruption in the Judiciary. Paper presented to 9th International Anti-Corruption Conference, Durban, South Africa.

[2] Alvarez, F. and U. J. Jermann (2000). "Efficiency, Equilibrium and Asset Pricing with Risk of Default." Econometrica 68(4): 775-798.

[3] Ariyoshi, A., Habermeier, K., Laurens, B., Otker-Robe, I., Canales-Kriljenko, J. I., and A. Kirilenko (2000). "Capital Controls: Country Experiences with Their Use and Liberalization." International Monetary Fund Occasional Paper, 190.

[4] Cole, H. L. and W. B. English (1991). "Expropriation and Direct Investment." Journal of International Economics 30: 201-227.

[5] Cole, H. L. and W. B. English (1992). "Two-sided Expropriation and International Equity Contracts." Journal of International Economics 33: 77-104. 
[6] Chang, R. (1995). "Private Investment and Sovereign Debt Negotiations." International Economic Review 36(2): 387-405.

[7] Eaton, J. and R. Fernandez (1995). "Sovereign Debt." Handbook of International Economics. G. M. Grossman and K. Rogoff. Amsterdam, Elsevier. 3: 2031-2076.

[8] Hellwig, C. and G. Lorenzoni (2003) Bubbles and Private Liquidity. Unpublished paper, Princeton University.

[9] Jeske, K. (2001). Private International Debt with Risk of Repudiation. Federal Reserve Bank of Atlanta Working Paper 2001-16 .

[10] Kehoe, P. J. and F. Perri (2002). Competitive Equilibria with Limited Enforcement. Federal Reserve Bank of Minneapolis Staff Report 307.

[11] Kehoe, T. J. and D. K. Levine (1993). "Debt-Constrained Asset Markets." Review of Economic Studies 60: 865-888.

[12] March, R. M. (1979). "An Analysis of the 1976-77 Japan-Australia Sugar Dispute." Australia-Japan Economic Relations Research Papers 56: 1-20.

[13] Townsend, R. M. (1980). "Models of Money with Spatially Separated Agents." Models of Monetary Economies. J. H. Kareken and N. Wallace. Minneapolis, Federal Reserve Bank of Minneapolis: 265-313. 